\title{
Birth defects: etiology to prevention
}

Koumudi Godbole

From International Conference on Human Genetics and 39th Annual Meeting of the Indian Society of Human Genetics (ISHG)

Ahmadabad, India. 23-25 January 2013

Structural birth defects together of are a prominent cause of mortality and morbidity and are gaining importance with improving obstetric care and reduction in infective causes. Advances in understanding genetic $(G)$ and environmental $(E)$ factors and their interaction have added newer dimensions to the etiology of birth defects. Epigenetic is one such interesting field expected to provide mechanistic links between whether and how the environment interacts with maternal and fetal genomes. Some classical examples of environmental insults such as teratogens, maternal medical disorders and nutritional deficiencies as well as G-E interactions leading to birth defects will be discussed. It is important that the relevant scientific information should reach professionals and public for better awareness, appropriate policy decisions to prevent birth defects.

Published: 21 January 2014

doi:10.1186/1755-8166-7-S1-124

Cite this article as: Godbole: Birth defects: etiology to prevention.

Molecular Cytogenetics 2014 7(Suppl 1):124.

Correspondence: koumudig@rediffmail.com

Deenanath Mangeshkar Hospital and Research Center, Erandawane, Pune, India

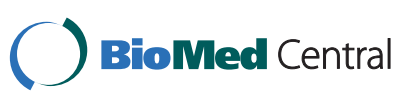

(0) 2014 Godbole; licensee BioMed Central Ltd. This is an Open Access article distributed under the terms of the Creative Commons Attribution License (http://creativecommons.org/licenses/by/2.0), which permits unrestricted use, distribution, and reproduction in any medium, provided the original work is properly cited. The Creative Commons Public Domain Dedication waiver (http:// creativecommons.org/publicdomain/zero/1.0/) applies to the data made available in this article, unless otherwise stated. 